\title{
La web 'Etnobotànica dels Països Catalans': coneixement tradicional al servei de la societat
}

\author{
TERESA GARNATJE ${ }^{1, *}$, AIRY GRAS ${ }^{1, *}, J^{\prime} O S E P$ PARADA ${ }^{2}$, MONTSE PARADA $^{2}$ \\ \& JOAN VALLÈS ${ }^{2,3}$
}

\author{
${ }^{1}$ Institut Botànic de Barcelona (IBB, CSIC-Ajuntament de Barcelona), pg. del Migdia s.n., \\ Parc de Montjuïc, ES-08038 Barcelona, Catalunya, Espanya \\ ${ }^{2}$ Laboratori de Botànica - Unitat associada CSIC, Facultat de Farmàcia i Ciències de l'Alimentació - Institut \\ de la Biodiversitat IRBio, Universitat de Barcelona, av. Joan XXIII 27-31, E-08028 Barcelona, Catalunya \\ ${ }^{3}$ Secció de Ciències Biològiques, Institut d'Estudis Catalans, c. del Carme 47, E-08001 Barcelona, Catalunya \\ *Igual contribució
}

ORCID iD. T. GARNATJE: https://orcid.org/0000-0001-6295-6217, A. GRAS: https://orcid.org/0000-0002-2256-3256, J. PARADA: https://orcid.org/0000-0001-7260-8224, M. PARADA: https://orcid.org/0000-0003-0240-9486, J. VALLÈS: https://orcid.org/0000-0002-1309-3942

Autor per a la correspondència: joanvalles@ub.edu

Editor: S. Garcia

Rebut 3 març 2021; acceptat 15 abril 2021; publicat on line 29 setembre 2021

\begin{abstract}
'Etnobotany of the Catalan Countries' website: traditional Knowledge to the People.- We present in this work the 'Ethnobotany of the Catalan Countries' website (https://etnobotanica.iec.cat), an interactive tool to rediscover plant-related traditional knowledge. At the time of released, the website contains almost 80,000 entries with plant names and 55,000 with medicinal uses, and work is underway to introduce, in the next two years, about 30,000 entries for food uses and about 30,000 more for other uses and other information. These data come from more than 1300 interviews with almost 2000 informants from $c a .500$ municipalities in the Catalan language domain. The Catalan-language territories are at least among the best ethnobotanically-prospected areas in southern Europe, and there is still ongoing research. The information considered to date has originated around one hundred works, a list of which is available in the website itself. Regarding popular names, the most diverse taxa are Zea mays, Achillea millefolium, Cynara cardunculus, Hypericum perforatum and Ceterach officinarum. In terms of medicinal uses - the only ones currently listed-, the most reported taxa are Thymus vulgaris, Sambucus nigra, Olea europaea subsp. europaea var. europaea, Matricaria recutita and Rosmarinus officinalis. This website is a good tool to feed back to society knowledge about its natural and cultural heritage, while preserving it and making it available for the new generations. In addition, this work will allow researchers to detect gaps in ethnofloristic research, to carry out meta-analyses (rarely conducted in ethnobotany) and to provide information to public and private stakeholders interested in developing commercial plant-based products.
\end{abstract}

Key words: biodiversity; Catalan countries; ethnobotany; medicinal uses; traditional knowledge; vernacular names.

\section{Resumen}

La web 'Etnobotànica dels Països Catalans': conocimiento tradicional al servicio de la sociedad.- Presentamos en este trabajo la web 'Etnobotánica de los Países Catalanes' (https://etnobotanica.iec.cat), una herramienta interactiva para redescubrir el saber popular sobre las plantas. En el momento de hacerse pública, contiene casi 80.000 entradas con nombres de plantas y 55.000 con usos medicinales, y se trabaja para introducir, en los próximos dos años, unas 30.000 entradas de usos alimentarios y unas 30.000 más de otros usos y otras informaciones. Estos datos provienen de más de 1300 entrevistas realizadas a casi 2000 informantes de alrededor de 500 municipios del dominio lingüístico catalán. Los territorios de lengua catalana se encuentran entre las áreas del sur de Europa mejor prospectadas etnobotánicamente, y actualmente sigue habiendo investigaciones activas. La información hasta ahora volcada ha originado un centenar de obras, cuya lista se puede consultar en la misma web. En cuanto a nombres populares, los táxones con mayor diversidad son Zea mays, Achillea millefolium, Cynara cardunculus, Hypericum perforatum y Ceterach officinarum. En cuanto a 
usos medicinales -los únicos que por el momento figuran-, los táxones más reportados son Thymus vulgaris, Sambucus nigra, Olea europaea subsp. europaea var. europaea, Matricaria recutita y Rosmarinus officinalis. Esta página web es una buena herramienta para el retorno a la sociedad de un saber sobre los patrimonios natural y cultural que de ella proviene, conservándolo y poniéndolo al alcance de las nuevas generaciones y, además, permitirá detectar huecos en la investigación etnoflorística, realizar metanálisis hasta ahora muy raramente hechos en etnobotánica y suministrar información a instituciones y empresas interesadas en desarrollar productos comerciales a base de plantas.

Palabras clave: biodiversidad; conocimiento tradicional; etnobotánica; nombres populares; Países Catalanes, usos medicinales.

\begin{abstract}
Resum
La web 'Etnobotànica dels Països Catalans': coneixement tradicional al servei de la societat.- Presentem en aquest treball la web 'Etnobotànica dels Països Catalans' (https://etnobotanica.iec.cat), una eina interactiva per a redescobrir el saber popular sobre les plantes. En el moment de fer-se pública, conté gairebé 80.000 entrades amb noms de plantes i $55.000 \mathrm{amb}$ usos medicinals, i es treballa per a introduir-hi, en els propers dos anys, unes 30.000 entrades d'usos alimentaris i unes 30.000 més d'altres usos i altres informacions. Aquestes dades provenen de més de 1300 entrevistes realitzades a quasi 2000 informants de gairebé 500 municipis del domini lingüístic català. Els territoris de llengua catalana es troben entre les àrees del sud d'Europa més ben prospectades etnobotànicament, i actualment encara hi ha investigacions actives. La informació fins ara buidada ha originat un centenar d'obres, la llista de les quals es pot consultar a la mateixa web. Quant a noms populars, els tàxons amb més diversitat són Zea mays, Achillea millefolium, Cynara cardunculus, Hypericum perforatum i Ceterach officinarum. Pel que fa a usos medicinals -els únics que de moment hi figuren-, els tàxons més reportats són Thymus vulgaris, Sambucus nigra, Olea europaea subsp. europaea var. europaea, Matricaria recutita i Rosmarinus officinalis. Aquesta pàgina web és una bona eina per al retorn a la societat d'un saber sobre els patrimonis natural i cultural que en prové, tot conservant-lo i posant-lo a l'abast de les noves generacions i, a més, permetrà detectar buits en la investigació etnoflorística, dur a terme metanàlisis fins ara molt rarament fetes en etnobotànica i fornir informació a institucions i empreses interessades a desenvolupar productes comercials a base de plantes.
\end{abstract}

Paraules clau: biodiversitat; coneixement tradicional; etnobotànica; noms populars; Països Catalans; usos medicinals.

Cómo citar este artículo / Citation

Garnatje, T., Gras, A., Parada, J., Parada, M. \& Vallès, J. 2021. La web 'Etnobotànica dels Països Catalans': coneixement tradicional al servei de la societat. Collectanea Botanica 40: e006. https://doi.org/10.3989/collectbot.2021.v40.006

Copyright

(C) 2021 CSIC. This is an open-access article distributed under the terms of the Creative Commons Attribution 4.0 International (CC BY 4.0) License.

\section{INTRODUCCIÓ}

L'etnobotànica, terme encunyat per Harshberger (1896), és una ciència pluridisciplinària en la intersecció de les ciències naturals i les humanes i socials, que té com a objecte d'estudi la relació entre les persones i les plantes amb la finalitat de preservar el coneixement tradicional com a patrimoni natural i cultural de la societat. Durant molts anys els estudiosos d'aquesta disciplina es varen veure atrets per l'exotisme dels tròpics i les mal anomenades tribus primitives, però a partir de mitjan segle $\mathrm{XX}$ es va proposar que l'etnobotànica no s'havia d'ocupar únicament de l'estudi de les societats no industrialitzades, sinó de les societats humanes en general (Portères, 1961).

Els territoris de llengua catalana es troben entre les àrees més ben prospectades del sud d'Europa des d'aquest punt de vista, amb investigacions actives des del treball pioner de Font i Quer $(1916 a, b)$, passant per les primeres tesis doctorals, de Mulet (1990) i Muntané (1991), fins al dia d'avui (Vallès, 2019 i referències contingudes en aquest treball).

Els Països Catalans formen una unitat lingüística en la qual el català, amb tots els seus dialectes i subdialectes, és la llengua comuna (Veny, 1982). Aquest és un fet rellevant, atès que la preservació dels noms populars de les plantes, i també dels usos que se'n fan, és un dels objectius primordials de l'etnobotànica. La riquesa de la llengua, especialment la que està relacionada amb les feines del camp i amb la ramaderia, ha disminuït dramàticament en les últimes dècades, coincidint amb l'abandonament progressiu del contacte amb la natura, amb l'èxode rural —que, tot i que durant la revolució industrial va començar a augmentar significativament, es va accelerar de manera irreversible durant la segona meitat del segle XX - i amb 
els canvis en les dinàmiques intergeneracionals de transmissió de la informació que, paradoxalment, s'han vist empobrides a causa de l'expansió de les tecnologies de la informació i la comunicació.

El relleu variat que mostra el territori, des del nivell del mar fins als $3150 \mathrm{~m}$, ofereix una gran riquesa florística. Els Pirineus, altres muntanyes com les serralades litoral i prelitoral, el massís de Penyagolosa i la serra de Tramuntana ocupen una porció important del territori. Les planes litorals, $\mathrm{amb}$ abundància de zones humides, entre les quals el delta de l'Ebre i les albuferes d'Alcúdia i València, i les planes de l'interior són igualment remarcables (Riba et al., 1976). Aquesta elevada diversitat geogràfica està associada a una àmplia gamma de zones climàtiques i això queda palès en el paisatge vegetal, que comprèn elements inclosos a les regions mediterrània, eurosiberiana i boreoalpina, amb elements que van des de comunitats del tipus de boscos de Quercus L. de fulla perenne a les planes litorals fins a prats alpins a les muntanyes altes, passant per comunitats forestals dominades per Quercus caducifolis, Fagus L., Pinus L. o Abies Mill., així com per matollars, màquies, prats secs, vegetació d'aiguamolls i altres tipus de comunitats (Bolòs et al., 2005).

La diversitat florística i la gran extensió del territori es posen de manifest en els resultats del diferents estudis etnoflorístics realitzats als Països Catalans. El mapa etnobotànic dels Països Catalans mostra una radiografia on les zones muntanyoses es troben àmpliament estudiades (Muntané, 1991, 2005; Agelet, 1999; Llongarriu \& Sala, 2005; Rigat et al., 2017; Aldea et al., 2019), dibuixant un mapa gairebé complet del Pirineu català (Gras et al., 2018). A Catalunya, la costa i les serralades (litoral i prelitoral) que s'estenen al llarg de la costa, des del Cap de Creus fins a les Terres de l'Ebre, també han estat prospectades en profunditat (Bonet, 1991, 2001; Selga, 1998; Parada, 2007; Bonet et al., 2008; Royo et al., 2008, 2009, 2010; Llurba, 2009; Saura, 2009; Batet et al., 2011; Talavera, 2018; Gras et al., 2019), així com també els altiplans i les conques de la Catalunya central (Raja, 2005) i les planes occidentals (Gras et al., 2020a). La Catalunya del Nord (Muntané, 1991, 2005; Parada, 2007), el País Valencià (Mulet, 1990; Pellicer, 2004) i les Illes Balears (Carrió, 2013; Mayans, 2013) també han estat objectes d'àmplies recerques.
Un dels objectius i alhora un deure de l'etnobotànica és el retorn del saber popular a la societat (CDB, 2019). Per aquest motiu, el nostre grup de recerca (www.etnobiofic.cat) ha creat una web (https://etnobotanica.iec.cat) que pretén recollir tota la informació compilada a partir de treballs etnobotànics propis $i$ aliens duts a terme en territoris de parla catalana amb l'objectiu de posar-la a disposició de la comunitat científica i de la ciutadania en general.

\section{MATERIAL I MÈTODES}

La major part de la informació que conté aquesta web ha estat recollida mitjançant entrevistes semiestructurades (Pujadas et al., 2004), un mètode d'ús corrent en etnobotànica i en altres disciplines, que consisteix a parlar de forma relaxada amb els informants, generalment, però no sempre, persones grans lligades a feines del camp o en alguns casos a altres activitats que incloguin coneixement tradicional relacionat amb les plantes. Les entrevistes no contenen preguntes tancades, però, a diferència de les no estructurades, en les quals l'informant parla del tot lliurement, en aquestes s'intenta dirigir-lo cap als temes sobre els quals es pretén obtenir informació (noms, usos, toxicitat, etc.). En la majoria dels treballs, la selecció dels informants no s'ha dut a terme de manera estocàstica, és a dir a l'atzar, sense una tria tipològica determinada a priori, sinó que es tendeix, com hem explicat abans, a buscar persones generalment d'edat avançada que tinguin o hagin tingut una relació molt directa amb la terra i les seves feines, o amb les plantes directament, bé perquè les usen, bé perquè n'han mantingut o en recorden el coneixement heretat. El mètode usat és el conegut amb el nom de bola de neu (Goodman, 1961; Bernard, 1998), en el qual cada persona informant pot dur, mitjançant contactes seus, a trobar-ne d'altres. Sempre que ha estat possible, s'han enregistrat les entrevistes, amb el consentiment previ dels informants (Rosenthal, 2006) i s'han dut a terme respectant els principis ètics de la Societat Internacional d'Etnobiologia (International Society of Ethnobiology, 2008). Totes les plantes citades en les entrevistes tenen un plec dipositat en un herbari de referència a fi que es pugui comprovar la correcta identificació de la planta esmentada. 
Les entrevistes gravades i posteriorment transcrites, així com també altres treballs aliens al nostre grup que segueixen aquesta metodologia, s'han entrat en una base de dades d'ús intern a partir de la qual s'ha creat la web que presentem. La Flora Manual dels Països Catalans (Bolòs et al., 2005) ha estat l'obra de referència per a la determinació $\mathrm{i}$ la nomenclatura dels tàxons $i$, per als que no hi figuren, s'ha seguit The Plant List (www.theplantlist. org). L'assignació dels tàxons a les famílies s'ha fet seguint el criteri de l'Angiosperm Phylogeny Group (APG IV, 2016).

Les característiques tècniques de la web són:

- Allotjament a un servidor Linux (sistema operatiu de tipus Unix, portable, multitasca i multiusuari) amb Apache. El servidor HTTP Apache és un servidor web HTTP (protocol de comunicació que permet les transferències d'informació mitjançant arxius) de codi obert.

- Desenvolupament en un entorn de treball CodeIgniter (de codi obert sota llicència Apache) amb llenguatges PHP (llenguatge de programació interpretat que s'utilitza per a generar pàgines web de forma dinàmica), HTML (llenguatge dissenyat per a estructurar textos i relacionar-los en forma d'hipertext), CSS (llenguatge de fulls d'estil), Javascript (llenguatge basat en objectes) i Jquery (biblioteca o marc de treball de Javascript).

- Base de dades MySql. És un sistema de gestió de bases de dades relacional multifil i multiusuari, que usa el llenguatge SQL (llenguatge estàndard de comunicació amb bases de dades relacionals), de gran velocitat a executar consultes $\mathrm{i}$ amb el suport per part del llenguatge PHP en l'elaboració d'aplicacions web, en l'entorn del programari lliure.

- Disseny responsiu seguint els estàndards del W3C (consorci internacional que treballa per a desenvolupar i promocionar estàndards per al World Wide Web).

El software de codi obert o programari lliure és aquell el codi font del qual forma part del domini públic, que podem usar, escriure, modificar i redistribuir lliurement. Aquest ha estat el motiu de l'elecció d'aquest sistema. El contingut d'aquesta web està protegit sota la llicència de Reconeixement-CompartirIgual 4.0 Internacional de Creative
Commons, en línia amb la idea d'accés obert, de ciència oberta, és a dir de posar a disposició pública el saber de la mateixa societat.

\section{ETNOBOTÀNICA DEL PAÏSOS CATALANS: COBERTURA DE LA WEB I GUIA D'ÚS}

La primera versió de la web Etnobotànica dels Països Catalans, que es pot visualitzar i utilitzar a la pàgina web https://etnobotanica.iec.cat, inclou treballs duts a terme al Principat, Catalunya del Nord, Illes Balears i País Valencià. Alguns són treballs molt exhaustius i que inclouen un territori extens, sovint coincident amb una comarca, mentre que d'altres són més locals. Aquesta cobertura es pot veure a la Fig. 1. La informació fins ara buidada ha originat un centenar d'obres, la llista de les quals es pot consultar a la mateixa web.

La web inclou informació sobre 1543 tàxons reportats en 1342 entrevistes realitzades a 1935 informants en 472 municipis. Les dades estan organitzades en sis grans categories: noms populars (79.706 reports), usos medicinals (54.893), usos alimentaris (uns 30.000 reports pendents de publicar), altres usos (uns 18.000 reports pendents de publicar), efectes nocius o tòxics (uns 2000 reports pendents de publicar), altres observacions (uns 10.000 reports pendents de publicar). Cada report és una aportació (un nom o un ús) feta per un informant referida a una planta. Tota aquesta informació, així com també una breu definició de què és l'etnobotànica, es pot trobar en la pàgina d'inici (Fig. 2).

La primera pestanya, sobre els noms populars de les plantes, permet fer dos tipus de cerques (Fig. 3). La primera opció és per nom popular, de manera que es pot escriure un nom popular i recuperar tots els tàxons que han estat designats amb aquest nom popular. Clicant a sobre del nom científic del tàxon s'obre una pàgina en la qual hi trobem, a més del nom, la família a la qual pertany, un seguit de fotografies de la planta i el total de noms populars citats per a aquest tàxon (amb el nombre de reports entre parèntesis). Aquests noms es poden ordenar alfabèticament o per nombre de reports i clicant a sobre d'un determinat nom obtenim els municipis on ha estat citat, representats sobre el mapa (Fig. 4). La 


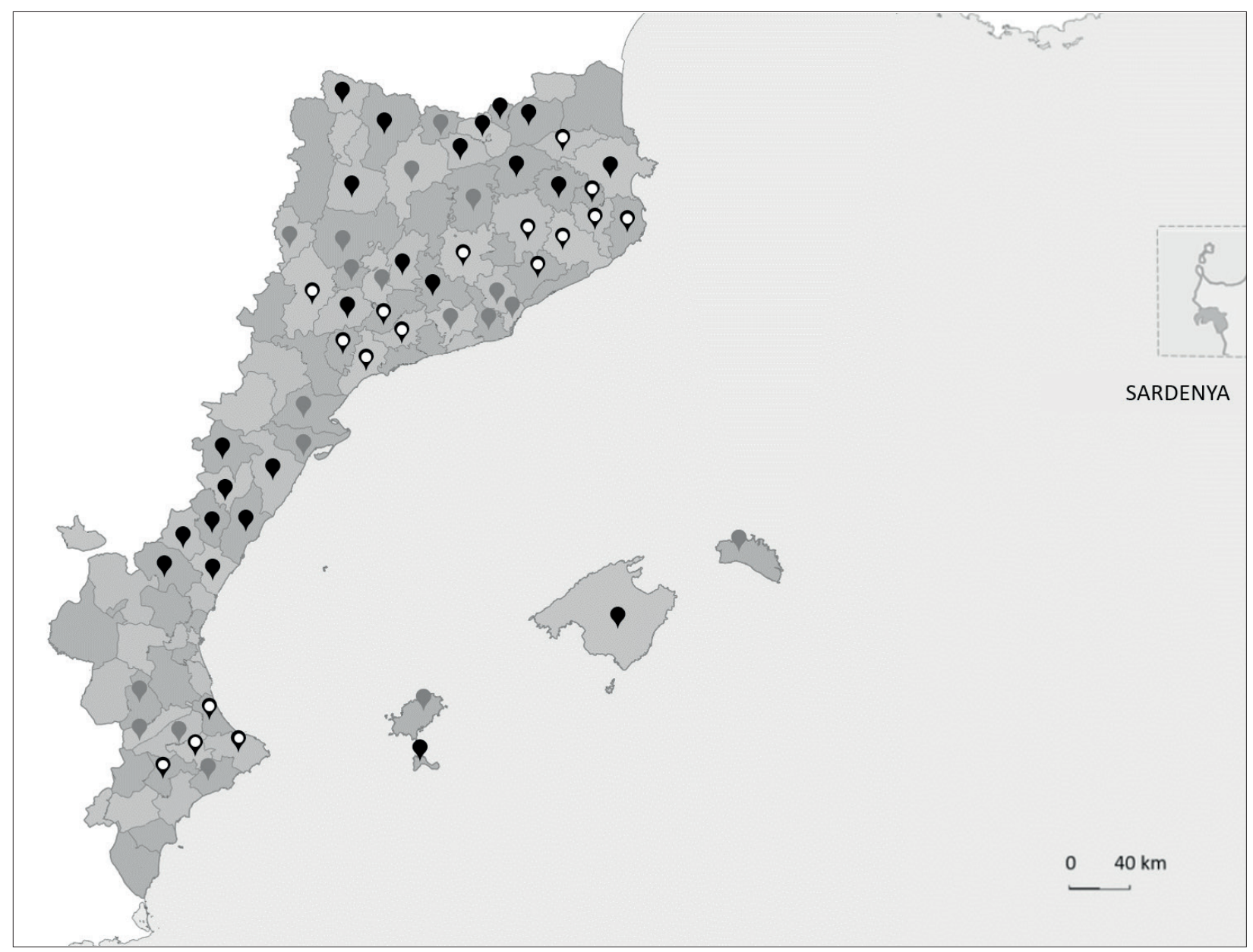

Figura 1. Cobertura de la web: versió actual $\bullet$ estudi d'abast comarcal o d'una illa, $\odot$ estudi d'abast menor que el comarcal; pròximes versions $\bullet$.

pestanya permet enllaçar directament amb els usos medicinals citats per a aquesta planta, $i$ també amb altres webs que poden resultar d'interès, com el catàleg de tàxons de l'associació Flora Catalana o Wikispecies.

La segona opció de cerca permet obtenir una llista de tots els tàxons que contenen informació sobre noms populars, que es pot ordenar per nombre de reports, per família o per tàxon. En la llista hi apareix una selecció dels noms populars seguits del nombre de reports entre parèntesis, però per a saber el nombre total de noms populars cal clicar el tàxon en concret. Un cop aquí, el procediment és igual que en la cerca anterior.

Els tàxons més citats quant a noms populars són Thymus vulgaris L. (1326 reports), Sambucus nigra L. (1234), Rosmarinus officinalis L. (1119), Olea europaea L. subsp. europaea var. europaea
(1110) i Zea mays L. (1053). Paral·lelament, els tàxons amb més diversitat de noms són Zea mays L. (77 noms populars), Achillea millefolium L. (62), Cynara cardunculus L. (56), Hypericum perforatum L. (55) i Ceterach officinarum DC. in Lam. et DC. (55).

La segona pestanya (Fig. 5) correspon als usos medicinals, per als quals tenim tres opcions de cerca. La primera opció permet obtenir una llista de tots els usos agrupats en 21 trastorns o grans categories. Per a aquesta divisió s'ha tingut en compte els sistemes afectats (p. ex. trastorns del sistema cardiovascular) i altres grans grups de trastorns que no encaixen en aquesta divisió categorial (p. ex. infeccions/infestacions) seguint la classificació proposada per Cook (1985). Aquesta llista facilita la cerca directa per ús medicinal que es troba associada a aquesta opció. 


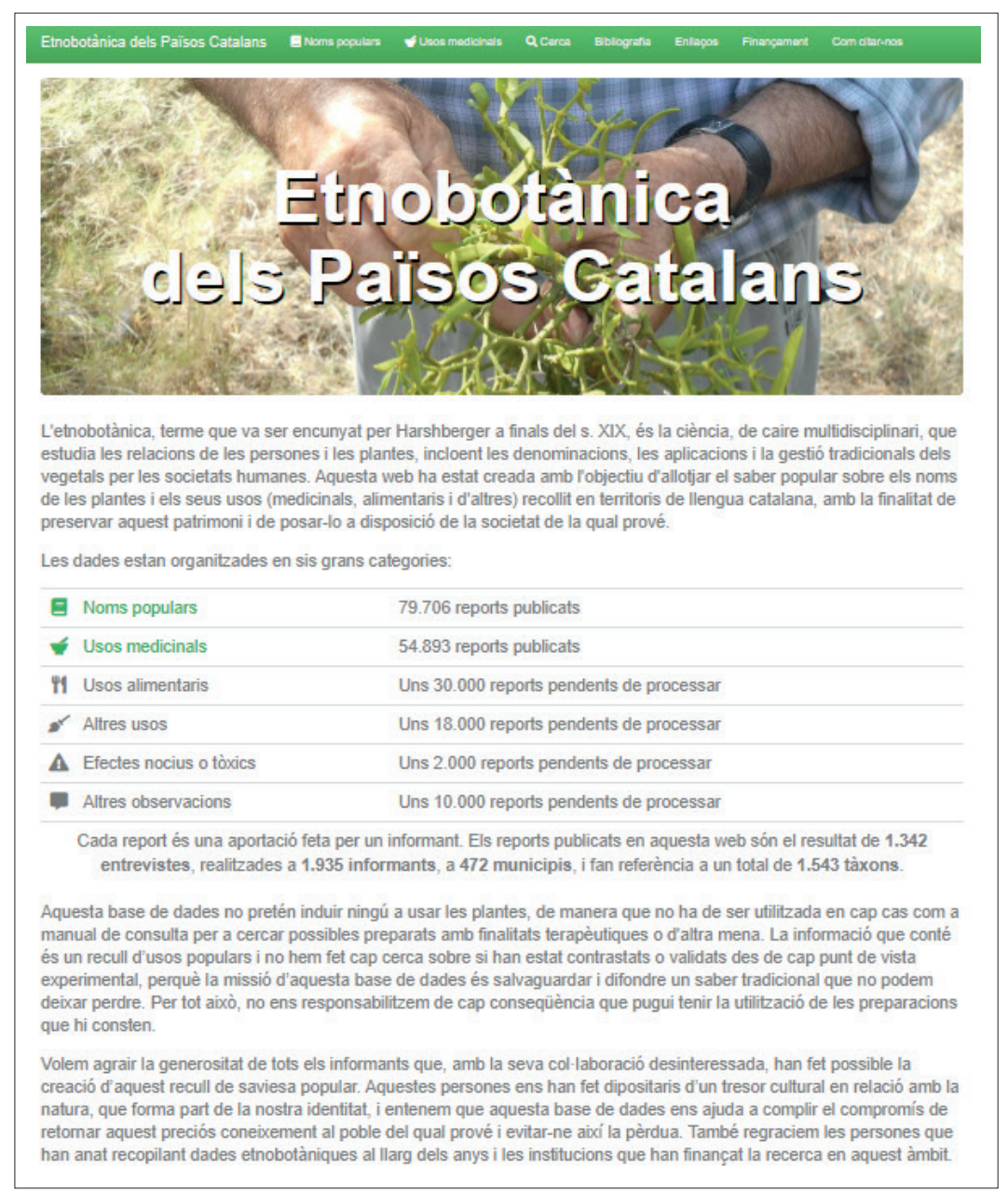

Figura 2. Pàgina d'inici de la web 'Etnobotànica dels Països Catalans'.

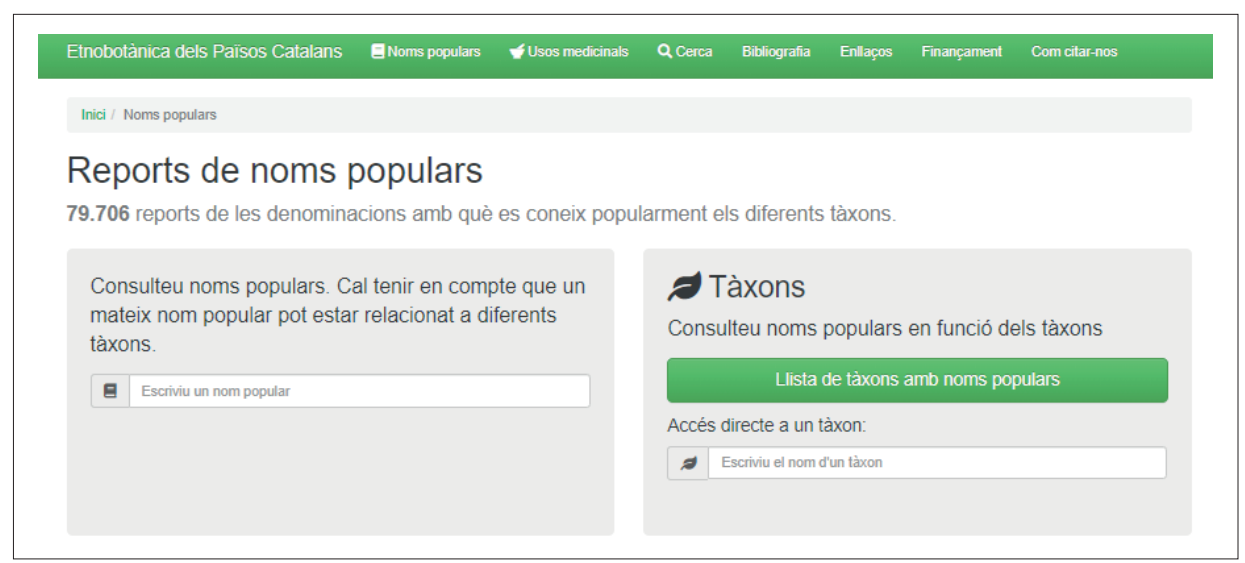

Figura 3. Captura de pantalla de la pestanya 'Noms populars'.

La segona opció permet fer una cerca per nom científic o nom popular o recuperar una llista de 1040 tàxons amb els principals usos medicinals, en la qual figura el nom científic de cada tàxon acompanyat del nombre de reports que té. De la mateixa manera que en els noms populars la informació es por ordenar per nombre de reports, família o tàxon. Per a cadascun dels tàxons, clicant a sobre del nom científic, podem veure tota la informació sobre usos medicinals. Aquesta està estructurada en diferents requadres on 


\section{$\approx$ Thymus vulgaris L.}

Hi ha 25 noms populars per a aquest tàxon

Farigola (526), Timó (284), Timonet (253), Frígola (125), Tomillo (castellà) (53), Farigoleta (20), Tomanil (17), Tremoncell (11), Tem (9), Thym (francès) (5), Timonet femella (4), Frigoleta (2), Timó mascle (2), Timol (2), Timon* (2), Timonet mascle (2), Timoncillo (castellà) (1), Cosconia (1), Farigola borda (1), Farigola de muntanya (1), Forigola (1), Frígol (1), Senyorida (1), Senyorida catalana (1), Timó femella (1)

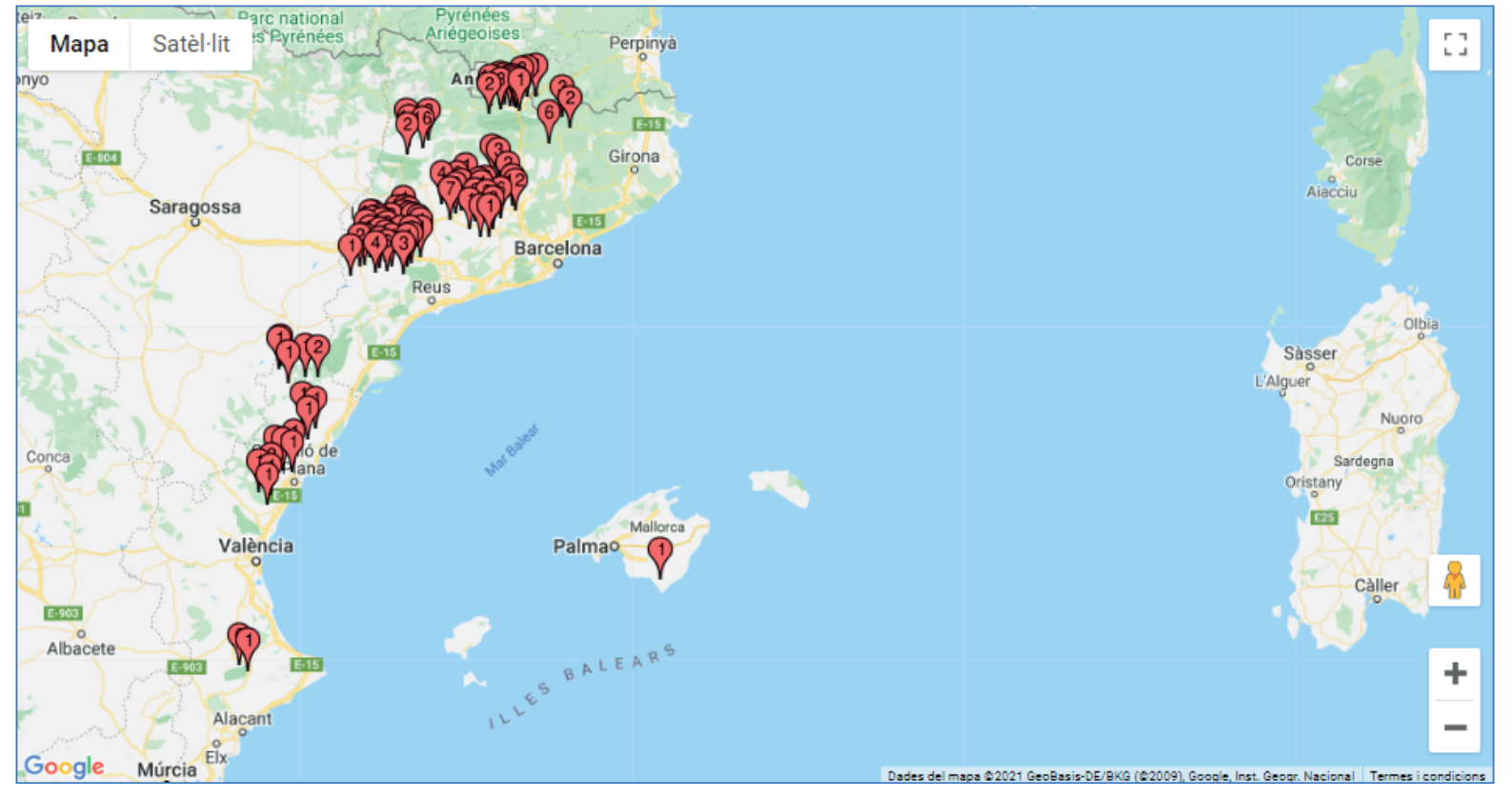

Figura 4. Distribució de citacions del nom popular 'timó' (Thymus vulgaris).

podem trobar informació sobre el municipi i la comarca on ha estat citada (p. ex. Atzeneta del Maestrat $\sim$ Alcalatén), el trastorn o gran categoria seguit de l'ús medicinal (p. ex. Inflamacions $\sim$ Antiinflamatori), la forma farmacèutica i/o d'aplicació (p. ex. Bany $\sim$ Ús extern), la destinació (medicina humana $o$ veterinària) $i$ els possibles efectes secundaris (Fig. 6). La possibilitat d'aplicar diversos filtres (comarca, aplicació, trastorn o destinació) permet afinar la cerca. Tal com s'ha mencionat també en els noms populars cada tàxon permet enllaçar amb un directori d'imatges, un mapa on hi ha representats tots els reports, un enllaç directe als noms populars i a altres webs d'interès. Per últim, la cerca avançada permet recuperar la llista completa de tots els usos, independentment dels tàxons, i a partir d'aquí aplicar els diferents filtres per a afinar la cerca.

Entre els tàxons més citats amb usos medicinals trobem Thymus vulgaris (2238 reports), Sambucus nigra (2134), Olea europaea subsp. europaea var. europaea (1278), Matricaria recutita L. (1178) i Rosmarinus officinalis (1132). Pel que fa als trastorns, els més reportats són aquells que tenen a veure $\mathrm{amb}$ afeccions relacionades amb el sistema digestiu (12.768 reports), la pell o el teixit subcutani (6733) i el sistema respiratori (6654).

La pestanya amb l'eina de 'Cerca' permet visualitzar la llista de tots els tàxons amb els nombres de noms populars i d'usos, i fer una cerca per gènere $i$ per espècie.

La pestanya de 'Bibliografia' conté el corpus bibliogràfic que actualment forma la web i a la d'Enllaços' s'hi ha inclòs una selecció d'altres webs que poden resultar d'interès per als usuaris d'aquesta web. La pestanya de 'Finançament' inclou una llista dels organismes i entitats que han finançat o financen aquest projecte. Per últim, a 'Com citar-nos' hi apareix una referència completa per tal de facilitar la difusió d'aquest projecte. 
Inici / Usos medicinals

\section{Reports d'usos medicinals}

54.893 reports d'usos medicinals.

\section{Usos medicinals}

Consulteu usos medicinals segons els trastorns

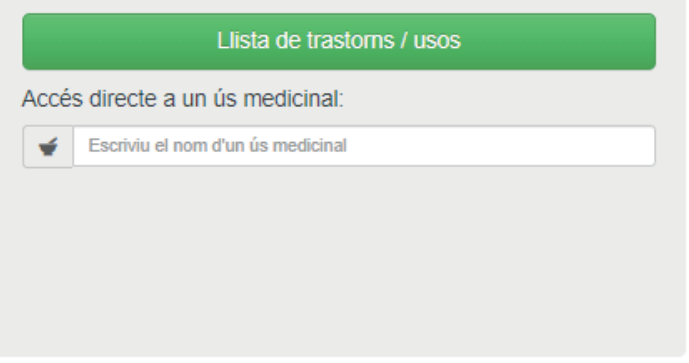

Tàxons

Consulteu usos medicinals en funció dels tàxons

\section{Llista de tàxons amb usos medicinals}

Accés directe a un tàxon:

Escriviu el nom d'un tàxon

O cerqueu el tàxon per nom popular:

E Escriviu un nom popular

\section{Q Cerca avançada}

Consulteu tots els reports disponibles

Figura 5. Captura de pantalla de la pestanya 'Usos medicinals'.

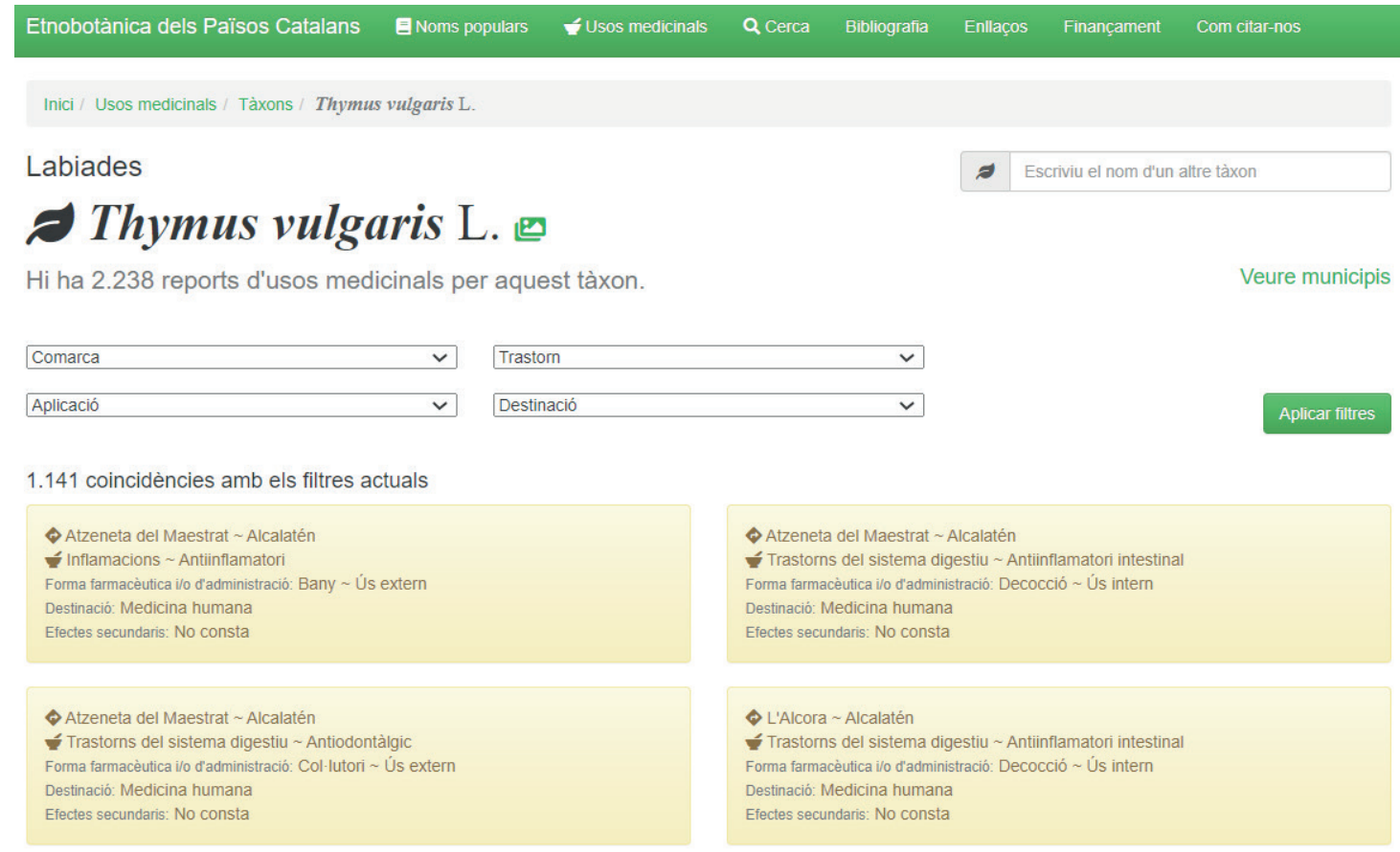

Figura 6. Usos medicinals citats per a Thymus vulgaris. 
A la part inferior de la pàgina web s'hi troba un formulari de contacte per tal de poder-nos fer arribar qualsevol suggeriment o pregunta.

La web 'Etnobotànica dels Països Catalans' és una recopilació de dades de cultura popular sobre la biodiversitat, però no pretén induir ningú a usar les plantes, de manera que no ha de ser utilitzada en cap cas com a manual de consulta per a cercar possibles preparats amb finalitats terapèutiques $o$ d'altra mena.

\section{CONCLUSIONS I PERSPECTIVES DE FUTUR}

Aquesta web és el resultat d'un esforç col-lectiu d'informants, investigadors i entitats finançadores de la recerca durant molts anys, tasca que continuarà els anys vinents amb la inclusió dels usos alimentaris (prevista per a 2022), altres usos, efectes nocius o tòxics $i$ altres observacions (2023), i amb noves actualitzacions de la versió actual dels noms i dels usos medicinals i dels altres que s'hi hagin anat introduint (regularment a partir de 2024).

Pel que fa a la recerca que continuarà alimentant aquesta web, la planificació de futur passa per dur a terme prospeccions que omplin forats en territoris del domini lingüístic català poc 0 gens estudiats, com l'Alguer, el Carxe o la Franja, així com completar-ne d'altres on s'ha fet o s'està fent treball de camp (Andorra, Alt Urgell, Baix Llobregat, Berguedà, Eivissa, Plana de Vic, Pla de l'Estany, Ribagorça, Sant Feliu Sasserra, serra de Collserola).

La pàgina web que hem presentat ha estat pensada perquè sigui una bona eina per al retorn a la societat d'un saber sobre els patrimonis natural i cultural que en prové, de tal manera que aquests coneixements que venen del passat es projectin al futur, és a dir es conservin i puguin ser accessibles a les generacions actuals i futures. A més, a partir de les dades que conté, permetrà aprofundir sobre aspectes concrets de la investigació en etnobotànica que ofereixen resultats prometedors. A part de detectar buits que cal cobrir en l'inventari etnoflorístic, permetran fer diversos tipus d'estudis metanalítics que fins ara han estat rars en aquesta disciplina, no només als Països Catalans, sinó en general: Pel que fa a l'àrea aquí considerada, el domini lingüístic català, en podem esmentar algun exemple: l'anàlisi de les formes vitals de les plantes i dels territoris fisiogràfics on creixen (Gras et $a l ., 2020 b$ ), l'estudi comparatiu de les plantes alimentàries silvestres (Gras et al., 2021a) i el paper de les famílies botàniques en l'etnobotànica mèdica (Gras et al., 2021b). Finalment, faran possible obtenir fàcilment informació sobre molt diversos tipus d'usos de plantes a institucions o empreses interessades a desenvolupar productes comercials d'origen vegetal en camps ben diversos, començant per la farmàcia i l'alimentació, però ni de bon tros aturant-s'hi.

\section{AGRAÏMENTS}

Els autors volen agrair profundament la col-laboració a tots els informants que al llarg de tants anys han preservat i compartit el seu saber, fent-ne possible la difusió a tota la societat. Igualment agraeixen a totes les persones que han dut a terme treballs etnobotànics en les àrees de parla catalana el seu esforç i el seu compromís amb el territori, i les que han contribuït a l'entrada de dades en la base de dades d'ús intern a partir de la qual s'ha creat aquesta web. També regracien en Xindes Sobrequés per les tasques informàtiques que han dut a terme, bàsiques per al funcionament de la web, i la Laura Calvet-Mir i en Juan José García-Granero pels suggeriments de millora del manuscrit. Finalment, agreixen el suport de les institucions que han finançat aquest projecte, especialment l'Institut d'Estudis Catalans (programes de recerca PRO2017-S02-VALLES i PRO2020-S02-VALLES), però també l'Agència de Gestió i Ajuts Universitaris i de Recerca, l'Ajuntament de Figueres, l'Ajuntament de Mollet del Vallès, el Centre d'Estudis Comarcals del Ripollès, el Departament de Cultura de la Generalitat de Catalunya, el Departament de Territori i Sostenibilitat de la Generalitat de Catalunya, l'Institut d'Estudis Empordanesos i l'Institut Ramon Muntaner - Fundació privada dels Centres d'Estudis de Parla Catalana. L'Airy Gras ha tingut una beca predoctoral (APIF) de la Universitat de Barcelona i un contracte postdoctoral a càrrec del projecte CGL2017-84297-R (Ministerio de Ciencia, Innovación y Universidades, Gobierno de España).

\section{REFERÈNCIES BIBLIOGRÀFIQUES}

Agelet, A. 1999. Estudis d'etnobotànica farmacèutica al Pallars. Tesi Doctoral, Universitat de Barcelona, Barcelona. Aldea, C., Almeida, B., Garnatje, T. \& Vallès, J. 2019. Estudi etnobotànic ena Val d'Aran. Sabença populara e patrimoni naturau e culturau. Universitat de Barcelona Edicions, Barcelona.

APG IV [Angiosperm Phylogeny Group] 2016. An update of the Angiosperm Phylogeny Group classification for the orders and families of flowering plants: APG IV. Botanical Journal of the Linnean Society 181: 1-20. https://doi.org/10.1111/boj.12385

Batet, D., Cartanyà, J., Castells, R., Piñas, I. \& Salat, X. 2011. Etnobotànica a les muntanyes de Prades. Centre d'Història Natural de la Conca de Barberà, Montblanc. 
Bernard, H. R. 1998. Handbook of methods in cultural anthropology. AltaMira Press, Walnut Creek.

Bolòs, O. de, Vigo, J., Masalles, R. M. \& Ninot, J. M. 2005. Flora manual dels Països Catalans (3a ed.). Editorial Pòrtic, Barcelona.

Bonet, M. A. 1991. Estudis etnobotànics a la vall del Tenes (Vallès Oriental). Tesi de Llicenciatura, Universitat de Barcelona, Barcelona.

Bonet, M. A. 2001. Estudi etnobotànic del Montseny. Tesi Doctoral, Universitat de Barcelona, Barcelona.

Bonet, M. A., Roldán, M., Camprubí, J. \& Vallès, J. 2008. Etnobotànica de Gallecs. Plantes $i$ cultura popular al Baix Vallès. Centre d'Estudis Molletans, Mollet del Vallès.

Carrió, E. 2013. Contribució a l'etnobotànica de Mallorca. La biodiversitat vegetal $i$ la seva gestió en una illa mediterrània. Tesi Doctoral, Universitat de Barcelona, Barcelona.

CDB [Convenio sobre la Diversidad Biológica] 2019. Consultat el 17 de febrer de 2021, a https://www.cbd.int

Cook, F. E. M. 1985. Economic botany data collection standard. Royal Botanic Gardens, London.

Font, P. 1916a. La ciència d'en Sovatger. Butlletí del Centre Excursionista de la comarca de Bages 66: 142-145.

Font, P. 1916b. Botànica popular: la justa observació. Butlletí del Centre Excursionista de la comarca de Bages 67: 153-154.

Goodman, L. A. 1961. Snowball sampling. The Annals of Mathematical Statistics 32: 148-170. https://doi.org/10.1214/ aoms $/ 1177705148$

Gras, A., Garnatje, T., Aldea, C., Almeida, B., D'Ambrosio, U., Altimiras, J., Parada, M., Rigat, M. \& Vallès, J. 2018. Etnobotànica del Pirineu català: estat actual i propostes de futur. IBIX 10: 33-47.

Gras, A., Garnatje, T., Marín, J., Parada, M., Sala, E., Talavera, M. \& Vallès, J. 2021a. The power of wild plants in feeding humanity: A meta-analytic ethnobotanical approach in the Catalan linguistic area. Foods 10: 61. https://doi. org $/ 10.3390 /$ foods 10010061

Gras, A., Hidalgo, O., D’Ambrosio, U., Parada, M., Garnatje, T. \& Vallès, J. 2021 b. The role of botanical families in medicinal ethnobotany: A phylogenetic perspective. Plants 10: 163. https://doi.org/10.3390/plants10010163

Gras, A., Parada, M., Vallès, J. \& Garnatje, T. 2020b. Catalan ethnoflora: a meta-analytic approach to life forms and geographic territories. Journal of Ethnobiology and Ethnomedicine 16: 1-10. https://doi.org/10.1186/s13002-02000424-x

Gras, A., Serrasolses, G., Vallès, J. \& Garnatje, T. 2019. Traditional knowledge in semi-rural close to industrial areas: Ethnobotanical studies in western Gironès (Catalonia, Iberian Peninsula). Journal of Ethnobiology and Ethnomedicine 15: 19. https://doi.org/10.1186/s13002-019-0295-2

Gras, A., Vallès, J. \& Garnatje, T. 2020a. Filling the gaps: ethnobotanical study of the Garrigues district, an arid zone in Catalonia (NE Iberian Peninsula). Journal of Ethnobiology and Ethnomedicine 16: 1-15. https://doi.org/10.1186/ s13002-020-00386-0

Harshberger, J. W. 1896. Purposes of ethno-botany. Botanical Gazette 21: 146-54. https://doi.org/10.1086/327316

International Society of Ethnobiology 2008. International Society of Ethnobiology code of ethics (with 2008 additions). Consultat el 17 de febrer de 2021, a http://www.ethnobiology.net

Llongarriu, M. \& Sala, E. 2005. Herbes remeieres de la Garrotxa. Recull de medicina tradicional. Llibres de Batet, Olot.
Llurba, N. 2009. Estudi etnobotànic d'Ulldemolins (el Priorat). Treball Dirigit, Universitat de Barcelona, Barcelona.

Mayans, M. 2013. Estudi etnobotànic de Formentera. Treball Final de Màster, Universitat de Barcelona, Barcelona.

Mulet, L. 1990. Aportaciones al conocimiento etnobotánico de la provincia de Castellón. Tesi Doctoral, Universitat de València, València.

Muntané, J. 1991. Aportació al coneixement de l'etnobotànica de Cerdanya. Tesi Doctoral, Universitat de Barcelona, Barcelona.

Muntané, J. 2005. Etnobotànica, etnofarmàcia i tradicions populars de la Catalunya septentrional (Capcir, Cerdanya i Conflent). Tesi Doctoral, Universitat de Barcelona, Barcelona.

Parada, M. 2007. Estudi etnobotànic de l'Alt Empordà. Tesi Doctoral, Universitat de Barcelona, Barcelona.

Pellicer, J. 2004. Recerques etnobotàniques al territori diànic o comarques centrals valencianes. Tesi Doctoral, Universitat de València, València.

Portères, R. 1961. L'Ethnobotanique: place, objet, méthode, philosophie. Journal d'Agriculture Tropicale et Botanique Appliquée 8: 102-109. https://doi.org/10.3406/jatba.1961.6902

Pujadas, J. J., Comas d'Argemir, D. \& Roca, J. 2004. Etnografia. Universitat Oberta de Catalunya, Barcelona.

Raja, D. 1995. Estudis etnobotànics a la comarca de la Segarra. Tesi de Llicenciatura, Universitat de Barcelona, Barcelona.

Riba, O., Bolòs, O. de, Panareda, J. M., Nuet, J. \& Gosàlbez, J. 1976. Geografia fisica dels Països Catalans. Ketres Editora, Barcelona.

Rigat, M., Gras, A., Vallès, J. \& Garnatje, T. 2017. Estudis etnobotànics a la comarca del Ripollès (Pirineu, Catalunya, península Ibèrica). Collectanea Botanica (Barcelona) 36: e003. https://doi.org/10.3989/collectbot.2017.v36.003

Rosenthal, J. P. 2006. Politics, culture and governance in the development of prior informed consent in indigenous communities. Current Anthropology 47: 119-142. https://doi. org/10.1086/497670

Royo, F., Torres, L. de, Curto, R., Cardero, S., Beltran, J., Arrufat, M. \& Arasa, A. 2008. Plantes del Port, I. Equisets $i$ falagueres. Arbres i arbustos. Arbres monumentals. Grup de Recerca Científica "Terres de l'Ebre", Tortosa.

Royo, F., Torres, L. de, Curto, R., Cardero, S., Beltran, J., Arrufat, M. \& Arasa, A. 2009. Plantes del Port, II. Mates $i$ plantes herbàcies angiospermes dicotiledònies. Grup de Recerca Científica "Terres de l'Ebre”, Tortosa.

Royo, F., Torres, L. de, Curto, R., Cardero, S., Beltran, J., Arrufat, M. \& Arasa, A. 2010. Plantes del Port, III. Plantes herbàcies angiospermes monocotiledònies. Arbres singulars. Grup de Recerca Científica "Terres de l'Ebre”, Tortosa.

Saura, S. 2009. Usos i cultura popular de les plantes a les Gavarres. Consorci de les Gavarres, Monells.

Selga, A. 1998. Estudis etnobotànics a les Guilleries. Tesi de Llicenciatura, Universitat de Barcelona, Barcelona.

Talavera, M. 2018. La recuperació dels coneixements tradicionals relatius a la biodiversitat com a eina de desenvolupament de nous cultius amb espècies silvestres, i acceptació per part dels consumidors dels productes elaborats amb espècies silvestres $i$ varietats tradicionals. Estudi etnobotànic de la comarca de l'Anoia, desenvolupament de nous cultius amb espècies silvestres, $i$ acceptació per part dels consumidors dels productes elaborats amb espècies silvestres $i$ varietats tradicionals. Tesi Doctoral, Universitat de Barcelona, Barcelona. 
Vallès, J. 2019. Etnobotànica: persones, plantes, cultura i benestar. Aspectes generals, i situació i perspectives als Països Catalans. Institut d'Estudis Catalans, Barcelona.
Veny, J. 1982. Els Parlars Catalans. Síntesi de Dialectologia (3a ed.). Editorial Moll, Palma. 